\title{
CONHECIMENTO BOTÂNICO TRADICIONAL E CONSERVAÇÃO EM UMA ÁREA DE CAATINGA NO ESTADO DE PERNAMBUCO, NORDESTE DO BRASIL
}

\author{
Ulysses Paulino de Albuquerque ${ }^{1}$ \\ Laise de Holanda Cavalcanti Andrade ${ }^{12}$
}

Recebido em 20/07/2001. Aceito em 18/12/2001.

\begin{abstract}
RESUMO - (Conhecimento botânico tradicional e conservação em uma área de caatinga no estado de Pernambuco, Nordeste do Brasil). No presente trabalho, sintetiza-se algumas informações sobre o conhecimento botânico tradicional em uma comunidade rural situada no município de Alagoinha, agreste do estado de Pernambuco, como parte de um projeto etnobotânico desenvolvido na região. Utilizou-se uma boa variedade de métodos de pesquisa, incluindo levantamentos florísticos em sistemas agroflorestais e em vegetação natural. As pessoas identificam e/ou usam mais de 108 espécies de plantas distribuídas em 10 categorias: comida, medicinal, madeira (para combustível, construção etc), uso doméstico (tecnologia), forragem, veneno, repelente de inseto, ornamentação, sombra e místico. Discute-se as formas como os recursos da floresta estacional são utilizados e manejados, e a implicação disso na conservação da caatinga.
\end{abstract}

Palavras-chave - Florestas tropicais, conservação, conhecimento tradicional, etnobotânica

\begin{abstract}
Traditional botanical knowledge and conservation in an area of caatinga in Pernambuco state, Northeast Brazil). In this paper we synthesized information on the traditional botanical knowledge of a rural community in the municipal district of Alagoinha, Pernambuco state, as part of an ethnobotanical project developed in the area. We used a variety of research methods, including floristic surveys in agroforestry systems (homegardens) and in the natural vegetation. People identify and use over 108 plant species distributed in 10 categories: food, medicinal, wood (for fuel, construction etc), domestic use (technology), forage, poison, insect repellent, ornamental, shade and mystic. This work discusses the ways by which the forest resources are used and managed, and the implications for conservation of the caatinga.
\end{abstract}

Key words - Tropical forests, conservation, traditional knowledge, ethnobotany

\footnotetext{
${ }^{1}$ Universidade Federal Rural de Pernambuco, UFRPE, Dpt ${ }^{\circ}$ de Biologia, área de Botânica, R. Dom Manoel de Medeiros S/N, Dois Irmãos, Recife-PE, Brasil.

${ }^{2}$ Universidade Federal de Pernambuco, UFPE, CCB, Laboratório de Etnobotânica e Botânica Aplicada (LEBA), Departamento de Botânica, Cidade Universitária, CEP 50670-901, Recife, PE, Brasil.
} 


\section{Introdução}

A caatinga, como uma formação vegetal altamente ameaçada, está envolvida pela idéia da improdutividade, segundo a qual seria uma fonte menor de recursos naturais. Essa idéia parece estar sempre relacionada às áreas áridas e semi-áridas de todo o mundo. Comumente a caatinga está associada ao fornecimento de recursos madeireiros e medicinais, e pelas formas de obtenção de alguns desses produtos da natureza não se tem enxergado outra alternativa que não seja a proteção total das áreas remanescentes, principalmente quando se considera o uso intenso de algumas espécies que apresentam uma esparsa distribuição e/ou pequenas populações. Algumas questões se colocam prontamente quando se pensa na criação de áreas protegidas: quais os critérios que devem ser levados em consideração? Somente critérios biológicos podem responder satisfatoriamente a tal necessidade?

$\mathrm{O}$ que têm demonstrando as experiências com outros ecossistemas? Durante muito tempo se negligenciou o papel das populações locais na criação de áreas protegidas, e as conseqüências dessa falta de atenção estão bem explicitadas por alguns autores, como Diegues (1994). $\mathrm{O}$ conhecimento acumulado pelas populações locais constitui uma poderosa ferramenta da qual desenvolvimentistas e conservacionistas podem se valer no planejamento e manutenção dessas áreas. Begossi (1998) desenvolveu a questão ao abordar o caso das populações caiçaras e reservas extrativistas na floresta atlântica, e muitos outros autores têm levantado o tema sob diferentes aspectos, desde o saber das comunidades locais sobre o uso e manejo dos recursos naturais até as implicações éticas, biológicas e culturais frente à questão da conservação (Diegues 1994; Albuquerque 1999a,b; Begossi 1998; Adams 2000; Moreira 2000).

Todavia, como usar, coletar e manejar o saber local? A etnobiologia e a etnoecologia têm sido campos que vêm contribuindo no forneci- mento de dados que muitas vezes corroboram a idéia de que as práticas locais de indígenas ou campesinos são ecologicamente sustentáveis e podem fornecer alternativas para as práticas importadas pelos cientistas que não raro olvidam a realidade local. Um dos campos que mais progrediu nessas análises foi a etnobotânica, principalmente na região amazônica. Contudo, os trabalhos têm se limitado à região Norte do país (Silva 1997), e ecossistemas como a mata atlântica e a caatinga são ainda pobres em investigações da relação seres humanos/natureza. Qual a importância em se conhecer essa relação? Para combinar o saber científico com o saber local visando contribuir com o planejamento de estratégias de desenvolvimento. As populações locais são a chave para o sucesso desses programas; fica difícil administrar Unidades de Conservação se a comunidade local não deseja participar ou não se sente comprometida durante todo o processo.

Em se tratando disso, geralmente são dois os caminhos seguidos: o primeiro consiste em afastar as comunidades locais das áreas protegidas e limitar ou evitar o acesso aos recursos locais; o segundo é chegar na comunidade com as idéias e propostas construídas que vão além das reais necessidades e interesses das pessoas. Todavia, ainda é grande a discussão sobre a permanência ou não das populações locais nas unidades de conservação (cf. Adams 2000). Mesmo assim, saber a maneira como as pessoas se relacionam e utilizam os recursos pode resultar em vários benefícios. Muitas comunidades possuem sistemas próprios de manejo, resultado da experiência acumulada durante séculos de relação com os recursos, que permitem suprir suas necessidades com um prejuízo ambiental mínimo. Algumas dessas técnicas são mais produtivas do que as que os cientistas desejam aplicar, pois estão adaptadas às condições locais de clima, solo, vegetação etc. Assim, essas comunidades podem se constituir em bons modelos, sobre os quais o saber científico, historicamen- 
te construído, pode se basear. Isso já vem sendo feito em muitas áreas do conhecimento, como na busca de novos produtos naturais a partir do saber local.

Estudos etnobotânicos indicam que as pessoas afetam a estrutura de comunidades vegetais e paisagens, a evolução de espécies individuais, a biologia de determinadas populações de plantas de interesse, não apenas sob aspectos negativos como comumente se credita à intervenção humana, mas beneficiando e promovendo os recursos manejados. Aliás, o manejo de comunidades vegetais é uma prática comum entre os indígenas das regiões neotropicais, e a sustentabilidade dessas práticas, em pequena escala, já foi noticiada. Um breve resumo dessas práticas nas regiões tropicais pode ser encontrado em Albuquerque (1999b). Salick (1995) completa informando que a relação plantas/pessoas pode ser interpretada sob vários aspectos e que pode contribuir para o progresso, por exemplo, da ecologia evolutiva; esclarece que na ecologia genética as pessoas agem como agentes seletivos para as plantas; na biologia de populações, alterando ciclo de vida, padrões de mortalidade, reprodução e sobrevivência de populações de plantas; e na ecologia química, as pessoas modificam e tiram vantagem das defesas químicas das plantas para seu benefício.

Salick (1995) ainda alerta que as pessoas manipulam muitas variáveis das comunidades vegetais. No entanto, os estudos de ecologia de comunidades estão construídos sobre ecossistemas naturais, e o ser humano como um agente de mudanças não é enfocado. Sem dúvida, considerar como as pessoas usam os recursos e afetam as populações vegetais e paisagens pode ser útil na construção de modelos que agreguem um maior número de variáveis. Tudo isso acima foi dito para demonstrar a necessidade de tais abordagens para o ecossistema caatinga, pouco investigado do ponto de vista etnobotânico. A maioria das contribuições resume-se a listas de recursos úteis sem uma atenção mais especial so- bre a percepção dos recursos e o seu manejo pelas comunidades estudadas.

No presente texto, apresenta-se um resumo dos dados obtidos a partir de pesquisas exploratórias realizadas em uma área de caatinga em Pernambuco, levantando problemas e sugerindo alternativas para a questão da sustentabilidade e uso dos recursos desse bioma.

\section{Local de trabalho}

O município de Alagoinha, de $181 \mathrm{Km}^{2}$, está localizado no Nordeste do Brasil na sub-zona do agreste de Pernambuco (08027'59' S e $36^{0} 46^{\prime} 33^{\prime} \mathrm{W}$ ), distando 225,5 Km da capital deste estado (Fidem, 2001) (Fig. 1). O clima é semi-árido quente de baixas latitudes. Segundo a classificação de Köppen, esse clima enquadra-se no tipo BSHs'. A temperatura média anual é de $25^{\circ} \mathrm{C}$ e a precipitação pluviométrica anual é de $599 \mathrm{~mm}$, com chuvas distribuídas irregularmente durante $o$ ano. A vegetação natural consiste de floresta tropical seca do tipo caatinga arbórea hiperxerófila, a qual se caracteriza pela presença de espécies xerófitas e decíduas, bem como de representantes das famílias Cactaceae e Bromeliaceae que contribuem na formação da paisagem. Apresenta espécies que permanecem com folhas na estação seca, como é o caso do juá (Ziziphus joazeiro Mart.) ou parcialmente, como o umbu (Spondias tuberosa Arr. Cam.). O estrato herbáceo, efêmero, surge com vigor na estação chuvosa. Uma descrição mais detalhada da área de estudo pode ser consultada em Albuquerque (2001).

\section{Material e métodos}

Diferentes técnicas foram utilizadas durante os trabalhos de campo, realizando-se entrevistas com informantes em suas próprias residências, observação participante, amostragem de vegetação, e identificação e análise de sistemas agroflorestais praticados na região. Os infor- 


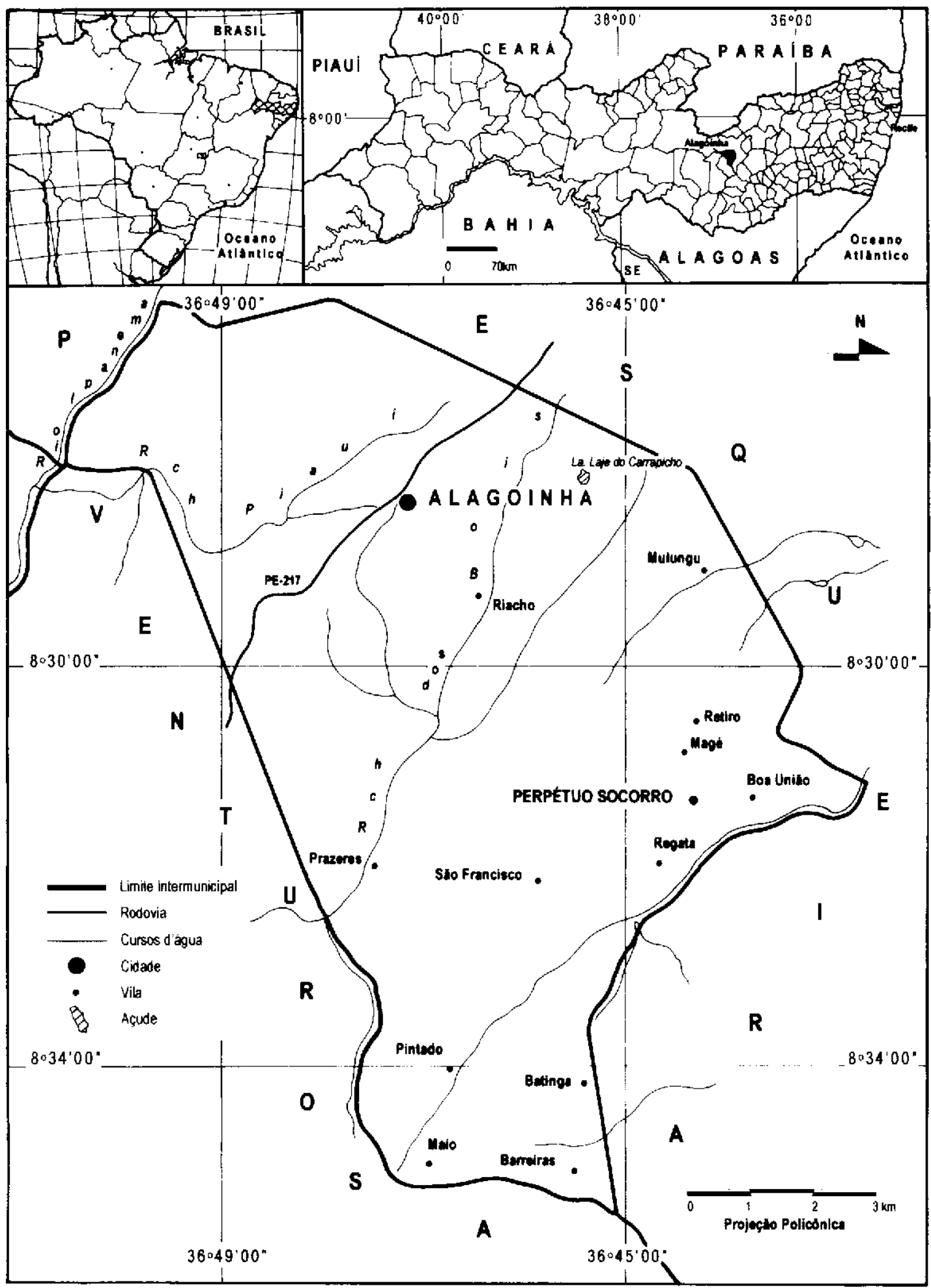

Fig. 1. Local de trabalho. Município de Alagoinha, estado de Pernambuco, Nordeste do Brasil. 
mantes foram questionados sobre as plantas conhecidas e o uso que se faz delas na região. Observações sobre práticas agrícolas e de manejo também foram processadas através de observação participante. Um detalhado levantamento etnobotânico foi obtido e todo o material botânico decorrente dele foi coletado com o auxílio dos informantes que identificaram as plantas no campo por seu nome vernáculo. Em outras situações amostras de plantas foram levadas diretamente para a identificação e apreciação dos informantes. Detalhamento dos procedimentos metodológicos podem ser encontrados em Albuquerque (2001).

\section{Resultados e discussão}

Como as comunidades que vivem na caatinga, ou nos seus domínios, se relacionam com os recursos vegetais?

A manipulação de plantas pelas pessoas em regiões semi-áridas depende de vários fatores que vão desde a disponibilidade temporal dos recursos até o grau de interesse por um recurso em especial. Parece existir diferentes padrões de uso e manejo dos recursos vegetais entre florestas úmidas e secas, ainda que não existam estudos específicos sobre o assunto. As formas de interesse e relacionamento com as plantas determinam diferentes graus de atenção (uma explicação um pouco mais extensa sobre isso se encontra em Caballero 1994; Albuquerque 1999b). As plantas podem ser coletadas, a partir de áreas de floresta primária, secundária, ou zonas antropogênicas (como margens de estrada, cultivos abandonados ou ativos), incluindo-se as obtidas a partir de uma prática extrativista amplamente disseminada. É o caso do umbu (Spondias tuberosa Arr. Cam.) e da aroeira (Myracrodruon urundeuva Fr. All.). Outras plantas são toleradas e protegidas, o que revela um grau maior de atenção por parte das pessoas. Aqui estão envolvidas as espécies que são toleradas em áreas de cultivo ou ao redor de casas e que não foram eliminadas por alguma razão especial, seja por suas propriedades medicinais, como o angico (Anadenanthera colubrina (Vell.) Brenan var. cebil (Griseb.) Altschul), ou pelo fornecimento de frutos e sombra, como é feito em relação ao mulungu (Erythrina velutina Willd.). Há ainda as plantas cultivadas que são de grande importância no semi-árido, como no caso da palma (Opuntia ficus-indica Mill.), sem falar das plantas silvestres favorecidas ou fomentadas que as pessoas manejam de forma a aumentar sua dispersão ou disponibilidade. Alguns estudos realizados no México têm apontado que esses diferentes graus de atenção podem afetar as plantas de diferente formas (Caballero 1994).

Além de todo esses aspectos, os sistemas agroflorestais constituem uma forma de manejar os recursos compatibilizando o cultivo, o pastoreio e práticas extrativistas. Nesses sistemas, há um consórcio de plantas silvestres, cultivadas e animais domésticos, e pelo menos a característica básica deles é a de subsistência da unidade familiar. Na verdade não existe um padrão rígido de organização desses sistemas, e dados e observações sugerem que existem algumas linhas evolutivas que conduziram a caminhos distintos de especialização. Alguns estão basicamente voltados para o comércio, predominando plantas frutíferas, raras silvestres e criação de animais domésticos. Outros combinam subsistência com produção para comércio, enquanto alguns estão voltados somente para a manutenção da unidade familiar. Todavia, na área estudada, a contribuição desses sistemas para a auto-suficiência alimentar de muitas famílias é quase nula, o que contrasta com alguns dos relatos coletados em várias partes do mundo.

Os sistemas agroflorestais são considerados uma alternativa para as regiões tropicais, e as comunidades que vivem nessas regiões desenvolveram sistemas adaptados às necessidades locais e características ambientais (Altieri 1988 ). Estudando esses sistemas e práticas, que estão in- 
seridos nos domínios da vegetação, é possível verificar as formas de uso, manejo, aproveitamento dos recursos, bem como os mais importantes, e a partir daí verificar o impacto das práticas locais sobre a vegetação e as melhores formas de intervenção local. Basicamente, as comunidades locais têm uma concepção sistêmica e conservacionista dos recursos, e alterações nesse modo de ver e se relacionar com os recursos vêm crescendo, como resultado de pressões externas a que as comunidades se encontram submetidas (interesses econômicos, pressões sociais, êxodo etc.). Todavia, é bom lembrar que nem todas as comunidades possuem atitudes conservacionistas e algumas de suas práticas são altamente agressivas.

\section{Como se dá a apropriação dos recursos da caa-} tinga?

A extração de produtos da floresta tem uma grande importância, variando de intensidade de acordo com a utilidade e disponibilidade do recurso. Entre estes recursos se incluem as madeiras, como a jurema (Mimosa tenuiflora (Willd.) Poir.) e os produtos medicinais, como o angico (Anadenanthera colubrina (Vell.) Brenan var. cebil (Griseb.) Altschul). A tab. 1 apresenta uma lista da diversidade de recursos e seus usos. Há muitos problemas sociais e econômicos relacionados a extração de recursos e uma carência de estudos que venham desvendar os fatores que se relacionam com algumas espécies em particular. Da caatinga se obtém além dos citados recursos, plantas forrageiras e alimentícias. A quantidade de recursos comestíveis é muito maior do que à primeira vista se poderia supor, pois as pessoas tendem a aproveitar uma gama muito maior cotidianamente ou quando submetidas a pressões diversas. Entre as plantas comestíveis encontram-se as frutíferas e as que fornecem raízes e folhas como verduras. A própria palma, que é usada como forragem, tem seus frutos bastante apreciados para o consumo humano. Muitos dos recursos poderiam ser melhor aproveitados para garantir às pessoas os meios de sobrevivência. Somando o saber tradicional sobre os recursos com o conhecimento científico, poderiam ser desenvolvidas técnicas para um melhor aproveitamento dos mesmos, ampliando as possibilidades de desenvolvimento local.

Muitos recursos medicinais da caatinga sofrem uma forte pressão extrativista não apenas pelo seu uso local, mas pela existência de um amplo mercado consumidor que se estende por todo o estado de Pernambuco. Esse comércio (formal ou informal) causa sério risco às populações dessas plantas, pois muitas vezes as pessoas envolvidas com a coleta desse recurso são descomprometidas e/ou desconhecem as técnicas adequadas de obter o produto desejado sem agredir as populações. Entre essas plantas pode-se destacar a aroeira, o mulungu, a baraúna, o angico e a imburana-de-cheiro. Alguns fatores são considerados capazes de comprometer a existência futura dessas plantas: 1 . intenso consumo; 2. ausência de cultivos ou pelos menos de alguma forma de propagação dessas plantas; 3 . uso para um mercado local, tradicional, e consumo por empresas para produção de fitoterápicos, o que exige grande quantidade de matéria-prima; 4. desconhecimento da distribuição e amplitude das populações naturais dessas plantas de interesse econômico; 5. ausência de estudos que avaliem o impacto das técnicas extrativistas na estrutura e biologia das populações.

\section{Como os recursos da caatinga são percebidos?}

Aqui se coloca uma questão de vital importância para as áreas de gestão e planejamento ambiental. A percepção das pessoas que vivem em um determinado ambiente, sobre os recursos locais é imprescindível no planejamento de estratégias, uma vez que é possível compreender melhor suas formas de relacionamento e condutas com relação a esses recursos. Quando se 
Tabela 1: Plantas usadas em uma comunidade rural do Município de Alagoinha, èstado de Pernambuco. Convenções, A: comestível; B: medicinal; C: madeira; D: uso doméstico (tecnologia); E: forragem; F: veneno; G: repelente de insetos; H: ornamentação; I: sombra; J: místicas. Fonte do recurso: a: quintais; b: mata; c: outras áreas antropogênicas; d: campos de cultivo.

\begin{tabular}{|c|c|c|c|}
\hline Táxons & Nome vulgar & Usos & Fonte \\
\hline \multicolumn{4}{|l|}{ Amaranthaceae } \\
\hline Amaranthus spinosus L. & Bredo-de-espinho & $\mathrm{A}, \mathrm{G}$ & $\mathrm{c}, \mathrm{d}$ \\
\hline Amaranthus viridis L. & Bredo-de-porco & A,G,E & $\mathrm{c}, \mathrm{d}$ \\
\hline Gomphrena vaga Mart. & Alento & B & $\mathrm{b}$ \\
\hline \multicolumn{4}{|l|}{ Anacardiaceae } \\
\hline Anacardium occidentale L. & Caju & $\mathrm{A}, \mathrm{B}$ & $\mathrm{a}$ \\
\hline Mangifera indica $\mathrm{L}$. & Manga & A & $\mathrm{a}$ \\
\hline Myracrodruon urundeuva (Engl.) Fr. All. & Aroeira & $\mathrm{B}, \mathrm{C}$ & $\mathrm{a}, \mathrm{b}$ \\
\hline Schinopsis brasiliensis Engl. & Braúna & $\mathrm{B}, \mathrm{C}$ & $\mathrm{a}, \mathrm{b}$ \\
\hline Spondias purpurea L. & Ciriguela & A & a \\
\hline Spondias tuberosa Arr. Cam. & Umbu & A & $\mathrm{a}, \mathrm{b}$ \\
\hline \multicolumn{4}{|l|}{ Annonaceae } \\
\hline Annona muricata L. & Graviola & A & $\mathrm{a}$ \\
\hline Annona squamosa $\mathrm{L}$. & Pinha & A & a \\
\hline \multicolumn{4}{|l|}{ Apocynaceae } \\
\hline Aspidosperma pyrifolium Mart. & Pereiro & $\mathrm{C}$ & $\mathrm{a}, \mathrm{b}$ \\
\hline \multicolumn{4}{|l|}{ Arecaceae } \\
\hline Bactris sp. & 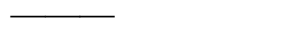 & I & $\mathrm{a}$ \\
\hline Cocos nucifera $\mathrm{L}$. & Coqueiro & A,I & $\mathrm{a}$ \\
\hline \multicolumn{4}{|l|}{ Asteraceae } \\
\hline Acanthospermum hispidum DC. & Espinho-de-cigano & B & $\mathrm{c}, \mathrm{d}$ \\
\hline Ageratum conyzoides $\mathrm{L}$. & $\longrightarrow$ & $\mathrm{B}$ & $\mathrm{c}$ \\
\hline Egletes viscosa Less. & Macela & B & $\mathrm{c}$ \\
\hline \multicolumn{4}{|l|}{ Bignoniaceae } \\
\hline Tabebuia sp. & Pau d'arco & $\mathrm{C}$ & a \\
\hline Tecoma stans Fuss. & Ipezinho & $\mathrm{H}$ & $\mathrm{a}$ \\
\hline \multicolumn{4}{|l|}{ Bombacaceae } \\
\hline Chorisia glaziovii (O. Kuntze) E.M. Santos & Barriguda & $\mathrm{H}, \mathrm{I}$ & a \\
\hline \multicolumn{4}{|l|}{ Boraginaceae } \\
\hline Cordia leucocephala Moric & Moleque-duro & $\mathrm{A}, \mathrm{C}$ & $\mathrm{b}$ \\
\hline Cordia globosa (Jacq.) H.B.K. & - & $\mathrm{C}$ & $\mathrm{b}$ \\
\hline Heliotropium indicum $\mathrm{L}$. & Fedegoso & $\mathrm{B}$ & $\mathrm{c}, \mathrm{d}$ \\
\hline \multicolumn{4}{|l|}{ Cactaceae } \\
\hline Cereus jamacaru DC. & Mandacaru & $\mathrm{A}, \mathrm{B}$ & $\mathrm{b}$ \\
\hline Opuntia ficus-indica Mill. & Palma & $\mathrm{A}, \mathrm{E}$ & $\mathrm{a}$ \\
\hline Melocactus zehntneri (Britton \& Rose) & Coroa-de-frade & A & $\mathrm{b}$ \\
\hline \multicolumn{4}{|l|}{ Lutzelb. } \\
\hline \multicolumn{4}{|l|}{ Caesalpiniaceae } \\
\hline Bauhinia cheilantha (Bong.) Steud. & Mororó & $\mathrm{A}, \mathrm{B}, \mathrm{C}$ & a,b \\
\hline Caesalpinia echinata Lam. & Pau-brasil & $\mathrm{H}, \mathrm{I}$ & $\mathrm{a}$ \\
\hline Caesalpinia ferrea Mart. & Jucá & B & $\mathrm{a}, \mathrm{b}$ \\
\hline
\end{tabular}


Tabela 1. (continuação)

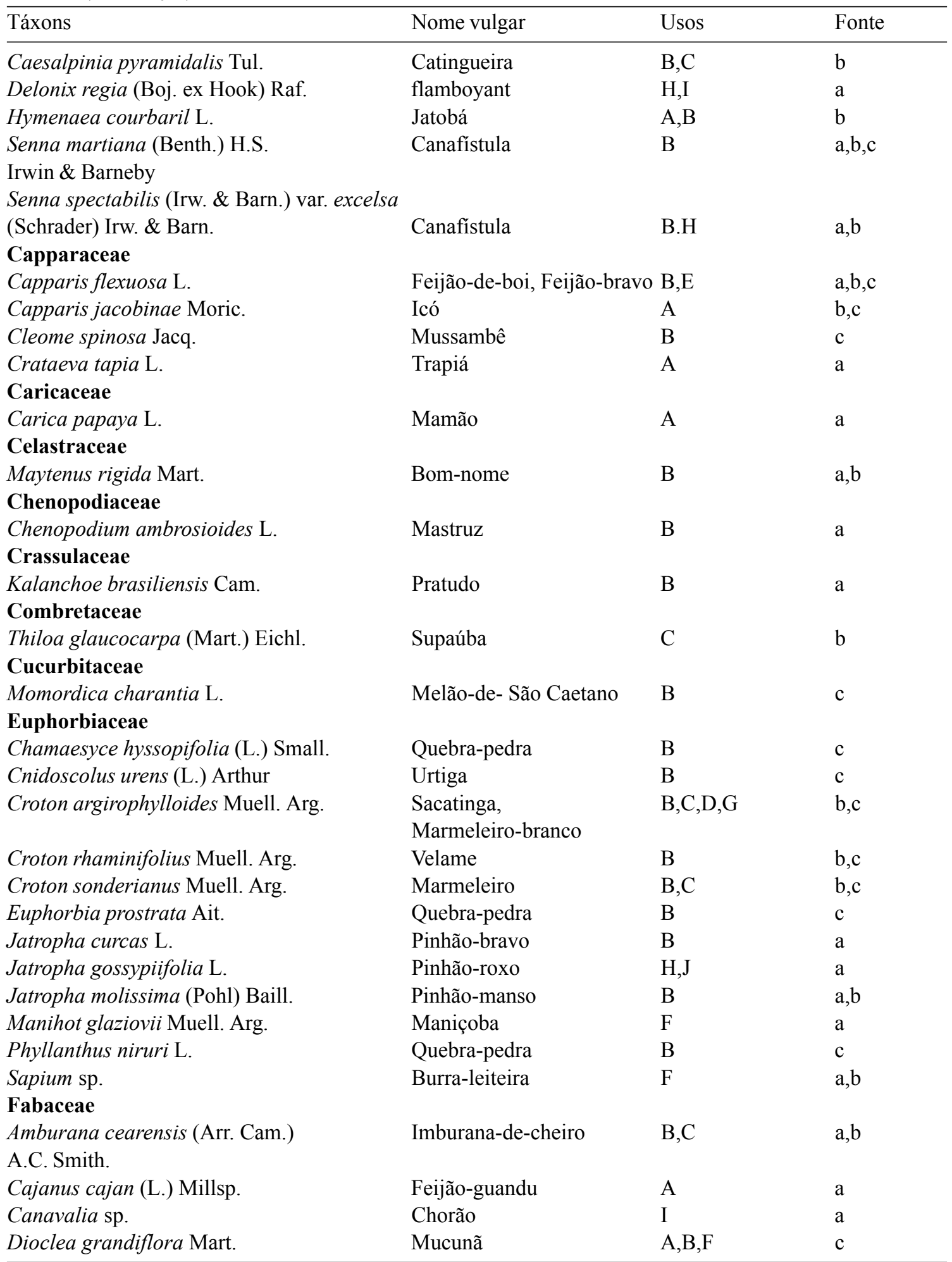


Tabela 1. (continuação)

\begin{tabular}{|c|c|c|c|}
\hline Táxons & Nome vulgar & Usos & Fonte \\
\hline $\begin{array}{l}\text { Erythrina velutina Willd. } \\
\text { Lamiaceae }\end{array}$ & Mulungu & $\mathrm{B}$ & a \\
\hline Ocimum campechianum Mill. & Mangericão & $\mathrm{B}$ & $\mathrm{a}, \mathrm{c}$ \\
\hline Plectranthus sp. & Hortelã & $\mathrm{B}$ & $\mathrm{a}$ \\
\hline $\begin{array}{l}\text { Rosmarinus officinalis L. } \\
\text { Malpighiaceae }\end{array}$ & Alecrim & B & $\mathrm{a}$ \\
\hline $\begin{array}{l}\text { Malpighia glabra } \mathrm{L} . \\
\text { Malvaceae }\end{array}$ & Acerola & A & a \\
\hline Gossypium herbaceum L. & Algodão & $\mathrm{H}$ & $\mathrm{a}$ \\
\hline $\begin{array}{l}\text { Hibiscus rosa-sinensis } \mathrm{L} \text {. } \\
\text { Mimosaceae }\end{array}$ & Papoula & $\mathrm{H}$ & $\mathrm{a}$ \\
\hline Acacia sp. & Avoador-vermelho & $\mathrm{C}$ & $\mathrm{a}$ \\
\hline $\begin{array}{l}\text { Anadenanthera colubrina (Vell.) } \\
\text { Brenan var. cebil (Griseb.) Altschul }\end{array}$ & Angico-de-caroço & $\mathrm{B}, \mathrm{C}, \mathrm{F}$ & $\mathrm{a}, \mathrm{b}$ \\
\hline Leucena leucocephala (Lam.) DC Witim & Leucena & E,I & $\mathrm{a}$ \\
\hline Mimosa $\mathrm{cf}$ malacocentra Mart. & Rasga-beiço & $\mathrm{C}$ & $\mathrm{b}$ \\
\hline Mimosa arenosa (Willd.) Poir. & Avoador & $\mathrm{C}$ & $\mathrm{b}$ \\
\hline Mimosa tenuiflora (Willd.) Poir. & Jurema-preta & $\mathrm{B}, \mathrm{C}$ & $a, b, c$ \\
\hline Piptadenia stipulacea Ducke & Carcará, rasga-beiço & $\mathrm{B}, \mathrm{C}$ & $a, b$ \\
\hline Piptadenia zehntneri Harms & Angico-liso & $\mathrm{C}$ & $\mathrm{b}$ \\
\hline $\begin{array}{l}\text { Prosopis julifora DC. } \\
\text { Myrtaceae }\end{array}$ & Algaroba & $\mathrm{A}, \mathrm{C}, \mathrm{E}$ & a \\
\hline Eucalyptus sp. & Eucalipto & $\mathrm{B}$ & a \\
\hline Eugenia sp. & Pirim & A & $\mathrm{a}$ \\
\hline Eugenia $\mathrm{sp}$. & Ubaia & A & $\mathrm{a}$ \\
\hline Eugenia uniflora L. & Pitanga & A & $\mathrm{a}$ \\
\hline Myrciaria caulifora Berg. & Jabuticaba & A & $a, b$ \\
\hline Psidium sp. & Araça & A & $\mathrm{b}$ \\
\hline $\begin{array}{l}\text { Psidium guajava } \mathrm{L} . \\
\text { Nyctaginaceae }\end{array}$ & Goiaba & A,B & a \\
\hline $\begin{array}{l}\text { Boerhavia diffusa } \mathrm{L} \text {. } \\
\text { Bougainvillea glabra Choisy }\end{array}$ & Pega-pinto & B & $\begin{array}{l}\mathrm{c} \\
\mathrm{a}\end{array}$ \\
\hline Oleaceae & & & \\
\hline $\begin{array}{l}\text { Jasminum sp. } \\
\text { Oxalidaceae }\end{array}$ & Jasmim & $\mathrm{H}$ & $\mathrm{a}$ \\
\hline $\begin{array}{l}\text { Oxalis insipida } \text { St. Hil. } \\
\text { Papaveraceae }\end{array}$ & Chumbinho & A & $\mathrm{b}$ \\
\hline $\begin{array}{l}\text { Argemone mexicana } \mathrm{L} \text {. } \\
\text { Passifloraceae }\end{array}$ & Cardo-santo & $\mathrm{B}$ & $\mathrm{c}$ \\
\hline $\begin{array}{l}\text { Passiflora foetida } \mathrm{L} . \\
\text { Poaceae }\end{array}$ & Maracujá-de-estalo & A,B & $\mathrm{b}$ \\
\hline Echinocloa colonum (L.) Link. & Unha-de-gato & B & $\mathrm{c}$ \\
\hline Cymbopogon citratus (DC) Stapf. & Capim-santo & B & $\mathrm{a}$ \\
\hline
\end{tabular}


Tabela 1. (continuação)

\begin{tabular}{|c|c|c|c|}
\hline Táxons & Nome vulgar & Usos & Fonte \\
\hline \multicolumn{4}{|l|}{ Polygonaceae } \\
\hline Ruprechtia laxiflora Meissn. & Caixão & $\mathrm{C}$ & $a, b$ \\
\hline \multicolumn{4}{|l|}{ Portulacaceae } \\
\hline Portulaca oleracea $\mathrm{L}$. & Beldroega & $\mathrm{B}$ & $\mathrm{c}$ \\
\hline \multicolumn{4}{|l|}{ Rhamnaceae } \\
\hline Ziziphus joazeiro Mart. & Juá & $\mathrm{A}, \mathrm{B}$ & $a, b$ \\
\hline \multicolumn{4}{|l|}{ Rutaceae } \\
\hline Citrus sp. & Limão & A & a \\
\hline Citrus aurantium $\mathrm{L}$. & Laranja & $\mathrm{A}, \mathrm{B}$ & $\mathrm{a}$ \\
\hline Citrus nobilis Lour & Laranja-cravo & A & a \\
\hline Ruta graveolens $\mathrm{L}$. & Arruda & $\mathrm{B}$ & a \\
\hline \multicolumn{4}{|l|}{ Sapindaceae } \\
\hline Sapindus saponaria $\mathrm{L}$. & Sabonete & $\mathrm{B}, \mathrm{D}$ & $\mathrm{a}$ \\
\hline Serjania comata Radlk. & Ariu & B & $\mathrm{c}$ \\
\hline Talisia esculenta (St. Hil.) Radlk. & Pitomba & A & a \\
\hline \multicolumn{4}{|l|}{ Sapotaceae } \\
\hline Sideroxylon obtusifolium (Roem. \& Schult.) & Quixaba & $\mathrm{A}, \mathrm{B}$ & $\mathrm{b}$ \\
\hline \multicolumn{4}{|c|}{ T.D. Penn. } \\
\hline \multicolumn{4}{|l|}{ Solanaceae } \\
\hline Capsicum parvifolium Sendt. & Pimenta-de-passarinho & $\mathrm{C}$ & $\mathrm{b}$ \\
\hline Solanum paniculatum $\mathrm{L}$. & Jurubeba & $\mathrm{B}$ & $\mathrm{c}$ \\
\hline \multicolumn{4}{|l|}{ Sterculiaceae } \\
\hline Melochia tomentosa $\mathrm{L}$. & Vermelhinho, malva & $\mathrm{B}$ & $\mathrm{b}, \mathrm{c}$ \\
\hline \multicolumn{4}{|l|}{ Verbenaceae } \\
\hline Lippia alba (Mill.) Brow. & Erva-cidreira & $\mathrm{B}$ & $\mathrm{a}$ \\
\hline Lippia sp. & Alecrim & $\mathrm{B}$ & $\mathrm{b}$ \\
\hline \multicolumn{4}{|l|}{ Violaceae } \\
\hline Hibanthus cf. ipecacuanha (L.) Baill. & Pepaconha & $\mathrm{B}$ & $\mathrm{c}$ \\
\hline
\end{tabular}

estuda percepção, o campo de enfoque é o processo mental, sendo por isso necessário uma adequada metodologia que vise cobrir todas as formas de expressão da percepção pelo ser humano. De modo geral, os grupos humanos que vivem em regiões de caatinga tendem a conceber os recursos vegetais dentro de um significado muito amplo de utilidade, que necessariamente não tem que ver com a compreensão dos cientistas. O significado de útil varia culturalmente (e intraculturalmente) e isso determina a forma com que as pessoas se relacionam com os recursos do ambiente. Para o sertanejo, todas as plantas da caatinga são consideradas úteis, sem que obrigatoriamente tenham uma utilização direta das pessoas. Todavia, essa percepção está relacionada com a visão de mundo e o próprio conhecimento do recurso por quem dele se utiliza, o que dita normas e padrões de conduta com relação a esses recursos. Muitos grupos indígenas do semi-árido pernambucano consideram a jurema (Mimosa tenuiflora (Willd.) Poir.) uma planta sagrada, cercada de profundo respeito e de todo um cerimonial, com as populações dessa planta tendendo a ser protegidas. Contudo, é uma planta muito apreciada pela qualidade de sua madeira, sendo muito utilizada para confecção de cercas e fabrico de carvão. 


\section{Padrões de manejo e uso de recursos.}

As pessoas na caatinga tendem a utilizar uma boa diversidade de produtos oriundos de variados sítios ecológicos (naturais ou manejados) como áreas de vegetação nativa, áreas perturbadas totalmente descaracterizadas, e de seus quintais (sistemas agroflorestais). As formas como as pessoas obtêm esses recursos, suas preferências e técnicas de manejo, refletem adaptações ecológicas, culturais, sociais e econômicas, a situações flutuantes relacionadas a pressões ambientais ou de mercado. Na tab. 1 são mostradas as 108 espécies identificadas neste estudo. Alguns produtos medicinais são mais abundantes nas proximidades das casas, todavia não parecem ter a preferencia das pessoas, como é o caso de espécies ruderais. Em muitas áreas são encontrados frutos comestíveis e os mais preferidos normalmente são observados em áreas perturbadas e/ou próximo aos campos de cultivo.

Outros produtos são coletados durante todo $\mathrm{o}$ ano, incluindo as plantas medicinais e madeiras, mas muitos produtos estão fortemente relacionados com uma pronunciada sazonalidade. Durante a ampla estação seca (que pode durar até oito meses) as pessoas dispõem principalmente dos troncos e ramos de árvores, e deles produzem medicamentos ou utensílios e materiais de construção, carvão etc. Nesse período há uma forte redução das atividades diárias e cresce progressivamente a busca de alternativas para os alimentos tradicionais. Nesse caso se estabelece o extativismo oportunístico de produtos que são coletados especialmente por mulheres e crianças. Todo esse comportamento descrito é muito semelhante ao relatado por Campbell et al. (1997) para uma área de savana no Zimbabue. Além disso, não há iniciativas de armazenamento de produtos e a comunidade aguarda as chuvas para garantir a colheita de suas lavouras policulturais. Suas práticas agrícolas e o seu modo de vida estão sendo fortemente ameaçados. Infelizmente não se dispõe aqui da história antiga da comunidade, o que permitiria avaliar com segurança os processos de manejo e cultivo implantados e praticados ao longo do tempo. Todavia é possível perceber o progresso crescente dos processos de conversão ambiental e de pobreza na área.

A região está sendo utilizada para extração de madeira com a ampliação das grandes propriedades. As pequenas propriedades que existem e que ainda mantêm seus sistemas e práticas tradicionais se vêem ameaçadas pela falta de incentivo e apoio, associados a própria desarticulação social e cultural que existe internamente. Os pequenos produtores estão abandonando seus sistemas e utilizando técnicas irracionais impostas por uma forte pressão econômica. Outros, por sua vez, abandonam suas propriedades que são posteriormente ocupadas por pessoas totalmente estranhas a comunidade, algumas vezes sem histórico de trabalho com a terra, que vivem em situação de miséria apesar de disporem de uma área útil e dos recursos naturais disponíveis. Quando se considera a sustentabilidade ecológica na região é preciso lembrar toda a sua heterogeneidade e que a dominância de determinadas espécies depende do local a ser estudado. Contudo, as pessoas têm percebido que muitos produtos declinaram com o tempo, principalmente algumas espécies frutíferas e que isso estaria relacionado mais com deflorestação do que com a sobrexploração.

\section{Conclusões}

Alguns problemas básicos que inicialmente nortearam o projeto de pesquisa que deu origem ao presente trabalho podem ser levantados e as conclusões subtraídas de suas respostas.

1. De que forma a comunidade aproveita os recursos da região? Os produtos obtidos dos recursos disponíveis na região são aproveitados para diversas finalidades, mas principalmente na medicina, tecnologia e produção de energia. Apesar da ampla variedade de recursos há uma 
pressão extrativista sobre uma minoria de espécies, enquanto outras, embora com usos conhecidos, são negligenciadas. Isso indica por um lado, dado as espécies preferidas, que a comunidade preserva o conhecimento sobre as espécies nativas da região, mas por outro, sofre privações em função dessa opção. Como o conhecimento desses recursos é estratificado e não existe uma rede de comunicação dentro da comunidade, o conhecimento botânico tradicional tende a se tornar cada vez mais restrito.

2. Aproveitando os recursos disponiveis, estes são diretamente utilizados no atendimento das necessidades gerais do grupo ou se convertem, em maior ou menor grau, em produtos de venda ou troca? Os recursos são usados na satisfação das necessidades básicas do grupo e só ocasionalmente, ou oportunisticamente, alguns são comercializados em feiras livres. Poucas pessoas cultivam fruteiras exclusivamente para finalidade comercial, restringindo-se a duas ou três espécies, e estando a colheita sujeita às intempéries ambientais.

3. Há diferenças etnoflorísticas dos recursos obtidos entre áreas de vegetação nativa e perturbadas? Se essas diferenças existirem, revelam preferências da comunidade na utilização de fitorecursos? Olhando os dados representados na tab. 1 fica fácil concluir que essas diferenças se referem tanto a composição florística quanto as categorias de uso, ou vocações utilitárias, desses dois locais, demonstrando que esse dado pode se constituir numa ferramenta importante para projetos de uso e manejo de recursos que se queira implantar ou desenvolver na localidade. As áreas perturbadas concentram espécies que podem ser sucedâneos eficazes para as espécies vulneráveis da vegetação nativa.

A literatura etnobotânica já vem relatando essas diferenças para muitas florestas tropicais; todavia as diferenças florísticas por si só não indicam preferência da comunidade por um determinado sítio ecológico. No caso da comunidade em questão, as pessoas preferem os recursos da vegetação nativa e isso é muito curioso, pois recursos de usos similares podem estar mais acessíveis e ainda são negligenciados. Esse comportamento difere do que é conhecido para muitos grupos humanos que habitam as regiões tropicais, sugerindo que estudos devem ser concentrados em comunidades que habitam regiões áridas ou semi-áridas para testar se esse comportamento é isolado ou reflete um padrão de comportamento das pessoas que habitam nesses ecossistemas.

4. A disponibilidade desses recursos e atendimento das necessidades do grupo obedece a fatores temporais? A preferência citada anteriormente parece ter suas bases assentadas na disponibilidade temporal e sazonalidade dos recursos. Na área estudada, os recursos das regiões perturbadas são em sua maioria herbáceos, de ciclo curto, disponíveis apenas no período das chuvas, enquanto os recursos usados da vegetação nativa são basicamente arbóreos e disponíveis durante todo o ano. Contudo, a satisfação das necessidades do grupo está relacionada a sua saúde, nos produtos medicinais, por que do ponto de vista alimentício a comunidade padece de grande necessidade, mesmo dispondo de recursos que brotam no período da chuvas. A maioria das pessoas desconhece a utilização desses recursos, e quando conhecem não providenciam seu armazenamento para os períodos em que não estarão disponíveis na natureza.

$\mathrm{Na}$ região muitos problemas foram identificados, sendo a retirada da cobertura vegetal o mais grave de todos, ao lado da difusão de tecnologias e atividades impróprias para a região. A subutilização dos espaços produtivos, como os quintais, revela uma agricultura extremamente deficiente e incapaz de atender as necessidades locais de alimento. As atividades desenvolvidas na comunidade são diversas, bem como a qualidade de vida alcançada pelos diferentes moradores. O primeiro passo para qualquer estratégia de desenvolvimento na região deve prioritariamente passar pela organização comunitária, 
para viabilizar a difusão das estratégias e tecnologias utilizadas com sucesso por algumas pessoas da região e seu conhecimento de plantas úteis. Há um grande potencial de inserção de produtos vegetais no mercado, além de seu aproveitamento nas atividades de subsistência. Todavia, a riqueza biológica da caatinga merece ser melhor estudada levando em consideração outros parâmetros socioculturais e ecológicos (grau de resiliência, por exemplo).

Por fim, considerando todos esses aspectos, é preciso incentivo para o desenvolvimento de estudos etnobiológicos na caatinga e em outras florestas secas como forma de se obter parâmetros para o conhecimento das estratégias de manejo e uso dos diferentes recursos. Além disso, um grande incentivo deve ser dado ao estudo dos sistemas agroflorestais tradicionais que são alternativas viáveis de uso da terra e que podem ser usados para garantir às pessoas o acesso a sua segurança alimentar. Atividades científicas e extensionistas devem ser desenvolvidas na região, numa mão dupla, envolvendo a comunidade e pesquisadores/extensionistas para o melhor conhecimento dos problemas da comunidade propiciando a sua organização em torno de objetivos comuns.

\section{Agradecimentos}

À comunidade estudada do município de Alagoinha pela hospitalidade e receptividade durante os trabalhos de campo, e pelos ricos momentos de aprendizado. Ao WWF (Fundo Mundial para a Natureza) e à USAID (Agência de Desenvolvimento Internacional dos Estados Unidos) pelo suporte financeiro para o desenvolvimento do projeto do qual este artigo é uma parte. À CAPES (Coordenação de Aperfeiçoamento de Pessoal de Nível Superior) pela bolsa de estudos concedida ao primeiro autor. Aos graduandos Fernando Valença, Cecília Almeida, Ana Carolina Silva, Fernanda Melo, Kátia Chisaki e Mirtes Guedes, pelo auxílio numa determinada etapa dos trabalhos de campo.

\section{Referências bibliográficas}

Adams, C. 2000. Caiçaras na mata atlântica: pesquisa científica versus planejamento e gestão ambiental. Annablume/FAPESP, São Paulo.

Albuquerque, U.P. 1999a. La importancia de los estudios etnobiológicos para establecimiento de estrategias de manejo y conservación en las florestas tropicales. Biotemas 12: 31-47.

Albuquerque, U.P. 1999b. Manejo tradicional de plantas em regiões neotropicais. Acta Botanica Brasilica 13: 307-315.

Albuquerque, U.P. 2001. Uso, manejo e conservação de florestas tropicais numa perspectiva etnobotânica: o caso da caatinga no estado de Pernambuco. Tese de Doutorado. Universidade Federal de Pernambuco, Recife.

Altieri, M.A. 1988. Sistemas agroecológicos alternativos para la producción campesina. Pp. 263-276. In: Desarrollo agrícola y participación campesina. Naciones Unidas y Comisión Económica para América Latina y el Caribe, Santiago de Chile.

Begossi, A. 1998. Extractive reserve in the brazilian Amazon: an example to be followed in the Atlantic Forest? Ciência \& Cultura 50(1): 24-28.

Caballero, J. 1994. La dimension culturelle de la diversité végétale au Mexique. Journal d'Agriculture Traditionel et de Botanique Appliqué 36: 145-158.

Campbell, B.M.; Luckert, M. \& Dcoones, I. 1997. Local-level valuation of savanna resources: a case study from Zimbabwe. Economic Botany 51(1): 59-77.

Diegues, A.C. 1994. 0 mito moderno da natureza intocada. NUPAUB, São Paulo.

Fidem. 2001. Fundação de Desenvolvimento Municipal. Perfil Municipal.

Moreira, A.C.C. 2000. Reserva extrativista do Bairro Mandira: a viabilidade de uma incerteza. Annablume/FAPESP, São Paulo.

Salick, J. 1995. Toward an integration of evolutionary ecology and economic botany: personal perspectives on plant/people interactions. Ann. Missouri Bot. Gard. 82: 25-33.

Silva, V.A. 1997. Etnobotânica dos índios Xucuru com ênfase às espécies da Serra do Ororobá (Pesqueira-PE). Dissertação de Mestrado. Universidade Federal de Pernambuco, Recife. 